\title{
At the nexus of problem-solving and critical research
}

\author{
Yahia Mahmoud $^{1}$, Anne Jerneck ${ }^{2}, \underline{\text { Annica Kronsell }}^{3,4}$ and Karin Steen $^{2}$
}

\begin{abstract}
The analytical distinction between critical and problem-solving research is useful. At the onset of research, the latter takes the world as it is while the former questions it. Yet, in striving to integrate social and natural dimensions of sustainability such a distinction may surface as a methodological obstacle. We illustrate how combining critical with problem-solving approaches can help us imagine, understand, and enable transitions to sustainability. First, we trace the historical divide and potential complementarity between critical and problem-solving approaches in the natural and social sciences and how critical approaches in the social sciences are informed by critical theory. Inspired by Robert Cox, we then analyze a set of PhD theses in an interdisciplinary research program engaging in critical and problem-solving research, on and for sustainability. We do so based on Cox's terminology, especially the concepts of ideas, institutions, material capabilities, and frameworks for action, and then show how selected research narratives apply them. To conclude, we emphasize that integrated understandings of human-environmental dynamics are facilitated by multiscalar approaches, theoretical and methodological pluralism, and a combination of natural and social science theory, typical of the interdisciplinary research field of sustainability science.
\end{abstract}

Key Words: human-environmental dynamics; interdisciplinarity; methodological pluralism; sustainability science; sustainability studies

\section{INTRODUCTION}

In this article we deal explicitly with the distinction as well as the dynamics between critical and problem-solving research. Based on a discussion of PhD work in sustainability studies, the overall aim is to stimulate critical problem-solving research for sustainability. In the past century, science was dominated by the view that its chief role was to study and solve problems and that these are the two means by which science, technology, education, and democratic societies progress (Agre 1982). Typically, and as expressed by political scientist Robert Cox (Cox 1981) a problemsolving approach takes the world as it is while critical research would question it in the quest for social change. We agree that although this distinction is analytically useful it is less relevant in sustainability research where scholars seek to solve complex human-environmental problems in the transition toward sustainable societies. In striving to integrate social and natural dimensions of sustainability the dualism in focus here may constitute an incommensurability between different ways of pursuing research in the natural sciences as compared to the social sciences (see Olsson and Jerneck 2018).

Proceeding from a foundational article for an interdisciplinary research program (LUCID, Lund University Centre of Excellence for integration of Social and Natural Dimensions of Sustainability) on social and natural dimensions of sustainability (Jerneck et al. 2011) and further inspired by a Coxian approach to the role of science (Cox 1981), we analyze 19 doctoral theses from this program engaging in critical and problem-solving research. The sample is exhaustive in terms of including all the theses completed until the time of the analysis (2013-2016; see Appendix 1). The objective of the analysis is to demonstrate that there are ways to overcome the potential dualism and fruitfully align or unite the two approaches in the service of incremental or radical transitions to sustainability. In particular, we will show if and how these researchers seek to combine critical with problem solving research and, more specifically, how they combine the objective to identify and critically evaluate a contemporary unsustainable phenomenon with the objective of proposing pathways to constructively deal with that challenge and issues associated with it.

\section{CRITICAL AND PROBLEM-SOLVING APPROACHES}

\section{Historical roots of the analytical distinction}

The debated division between critical and problem-solving approaches is a methodological issue with a long history. Among other things, science is a field of discussion and disputes where visions and worldviews are compared, defended, and contested. Clashes within and between scientific approaches, sometimes leading to paradigm shifts, are therefore both unavoidable and desirable. Although scientific controversies are as old as science itself it was mainly from the 1950s that modern science and the way it operates started to become widely scrutinized. For instance, Kuhn (1962:viii) identified signs of what he called paradigmatic shifts or scientific revolutions:

I was struck by the number and extent of the overt
disagreements between social scientists about the nature
of legitimate scientific problems and methods. Both
history and acquaintance made me doubt that
practitioners of the natural sciences possess firmer or
more permanent answers to such questions than their
colleagues in social science.

Other scholars (e.g., Popper, Feyerabend, Habermas, Morin) view such controversies as an expression of how ideological differences in society are reflected in the field of science, sometimes leading to fierce debates between perspectives (Morin 1992:380):

If science cannot be reduced to ideology ... one must nevertheless acknowledge the ideological component in all scientific knowledge. Scientific knowledge cannot be spared from ideological critique, and thus from selfknowledge and that also applies to those who think they possess the true science and denounce the ideology of others.

${ }^{1}$ Department of Human Geography, Lund University, Sweden, ${ }^{2}$ Centre for Sustainability Studies, LUCSUS, Lund University, Sweden, ${ }^{3}$ Department of Political Science, Lund University, Sweden, ${ }^{4}$ School of Global Studies, Gothenburg University, Sweden 
To exemplify, we refer to the critique against the grand narratives of social change and development that have dominated science since the Enlightenment (such as Marxism), and to the rise of competing but more partial theories and narratives from the 1950s (such as modernization theory, structuralism, etc). Here "newer" voices made their worldview and interests in equality, identity, power, and social inclusion paramount (e.g., Habermas and BenHabib 1981, Lyotard 1984, Foucault 2012). Besides the scale of the narrative, there is a dispute about the role of science in social life. Should science merely be an instrument serving specific needs defined by social actors? Or should it be a means for experiment and reflection opening up for radical ways to understand social life? Should society be seen as one unit, as a whole, or is it better understood in fragments, in parts? Depending on their approach to these (and other) questions, contemporary scientists will, explicitly or implicitly, position themselves or be positioned in that scientific field of disputes. In their effort to tackle the friction between critical and problem-solving research, the theses that we analyze in this study will offer new insights on how a new generation of researchers handle such questions.

\section{Cox on the analytical distinction}

Our research is inspired by arguments raised by Robert Cox (1981) in the article Social forces, States and World orders: Beyond International Relations Theory. Cox builds on a historical tradition from Braudel and Gramsci wherein scholars seek to understand the past and the present for the purpose of bringing about social change aimed at a new antihegemonic world order, preferably emerging from the bottom of civil society (see Brincat 2016). According to Cox a theory always involves a perspective; it is always for someone and for some purpose. In that respect he echoes Max Horkheimer's well-known view from the 1930s (Horkheimer 1972) that theories about society always include political motives. Further, Cox argues that there is no such thing as a theory in itself divorced from a standpoint in space and time (Cox 1981). In line with that, theory can serve two distinct objectives; it can be a problem-solving guide defined within the confines of a specific perspective, or be used to reflect upon the nature of that perspective itself. The first objective is associated with a problem-solving approach while the second objective is associated with critical theory. Whereas problem solving is mainly associated with a consensus view of society, critical theory argues that social conflicts entail the potential for change and transformation (Jones et al. 2011). As a special contribution to critical theory, and of importance for the focus here on transboundary human-environmental issues, Cox underlines that critical scholars need to take a multiscalar approach thus engaging with both global and local scales (see Brincat 2016).

The problem-solving approach tries to find solutions that do not disturb (or disturb the least) the prevailing socioeconomic order while critical theory is willing, if necessary, to question the prevailing order, often from a normative perspective. In this sense, the problem-solving approach is ahistorical because it does not concern itself with the origins and nature of the conditions that created the present social order (and its problems). It is also apolitical, not seeing problems as political in need of political recognition, representation, and action. Methodologically, problem-solving research is concerned with verification. It seeks to fill data into gaps in given frameworks or identify a puzzle where each added piece will serve to improve efficiency or reduce uncertainty (Gherardi and Turner 2002). In opposition, a critical theory approach always takes its starting point in the historical context that it attempts to both study and change. As a further contrast, critical research is more associated with discovery, be it of new (or hidden) social relations or of new, unexpected, and less obvious aspects of a particular phenomenon thus often requiring a reinterpretation or reframing of social reality (Gherardi and Turner 2002).

To take a bold example with reference to neoclassical economics versus economic history, we could apply Cox's distinction by saying that economics is a problem-solving and allegedly more parsimonious discipline that assumes a society striving for actions and policies that promote economic equilibrium. In contrast, economic history, and economic sociology, would take a comprehensive, long-term, and often more conflict-oriented and critical approach to the social and political role of the economy or its parameters (Granovetter 2017). Following upon its recognition of historical conditions and processes, critical research will often, if needed, deal with the problems at hand, such as the sustainability challenges that we face here, by considering how they interact with persistent social problems and thus also be open to fundamental social change (Jerneck et al. 2011).

Problem-solving and critical approaches in the natural sciences Scholars who are firmly grounded in the natural sciences may in an effort to study sustainability challenges tend to explain social and political processes using problem solving theories derived from the natural sciences, such as resilience theory, which is central in ecology (Scheffer 2009). But as Olsson et al. (2015) show it becomes problematic when resilience is imported into the social sciences where it appeals to some while at the same time stirring up old dust and methodological resistance from others (Joseph 2013). Some social scientists tend to portray the natural sciences as if they were operating exclusively under positivist paradigms that strive for scientific objectivity, reduced uncertainty, and scientific agreement (see Moses and Knutsen 2012). Similarly, much social science research is positivist, postpositivist, problem solving, or critical, but obviously not always informed by critical theory (see Moses and Knutsen 2012). Positivism as a scientific position goes back to Francis Bacon and August Comte maintaining that researchers can study the world in terms of its regularities and thus arrive at general rules. Based on scientific methods, researchers detect, observe, and analyze empirical data and thereby reveal how nature and society operate (e.g., Hay 2002, Moses and Knutsen 2012). The most convenient interdisciplinary collaboration may therefore be between social and natural scientists who adhere to a problem-solving approach. For example, actor-based models can attract collaborations between ecological modellers and mainstream economists because they both rely on basic assumptions of what drives behavior: economic choice, interests, and preferences in neoclassical economics, and selfish genes in evolutionary biology. Although this may result in an interdisciplinary match, it does not necessarily engage with critical approaches and only exemplifies one way in which social and natural science models can work together.

It can also be argued that when social scientists label natural science research as problem-solving research they may actually misrepresent it. If one of the hallmarks of critical approaches is 
to recognize that knowledge is situated and thus variable, then categorically labelling the natural sciences as problem solving is doubtful. For example, depending on theory and the method of observation we would think that electro-magnetic radiation behaves as either a wave or a particle (photon). This underscores the role of the observer as a participant in bringing forth seemingly opposing aspects of reality. Obviously, different interpretations of reality coexist also in the natural sciences to be called upon in different contexts depending on purpose or need. To briefly illustrate this, the application of classical Newtonian mechanics is vital for understanding orbital trajectories, while quantum mechanics explicitly invokes the role of observer agency for probing the fabric of matter.

A topic more relevant to sustainability would be humanenvironmental impacts of and social response to climate change, land use change, biodiversity loss, and water scarcity. Conventionally, predictive theories operate in a reductionist mode where their value is judged by clarity, simplicity, and fruitfulness (Khagram et al. 2010), or what others call parsimony (Hay 2002), and where the expected outcome is to reduce uncertainty and seek scientific agreement. Though predictive models have value, the acknowledgement of uncertainty regarding the future of the Earth's ecosystems and societies means that exploratory modeling approaches have now gained currency amongst natural scientists. Such frameworks often use different climate and land use models (uncertainty in model formulation) that are driven by multiple scenarios with contrasting assumptions about the economy/ society and climate. In this so-called deep uncertainty, emphasis is placed on structured analyses of outputs across multiple outcomes. In situations and under conditions where agreement is impossible, these approaches capitalize on future indeterminacy in developing policy insights for societal adaptation. It can be argued that these approaches maintain a problem-solving ambition in that they either use models originally developed for predictive purposes or identify invariant outcomes across a range of scenarios to anchor policy decisions, or both. Meanwhile, they represent valuable natural science knowledge.

In contrast, domestication of perennial grain is a clear example of critical natural science research. The dominance of annual crops is the root cause of agricultural unsustainability causing huge losses of soil, nutrients, and carbon because of the need to replant every year (Crews et al. 2014). An obvious problem solving approach would be to replace annual grains with perennials. But domestication and breeding of perennial grain crops is a costly long-term project and for several reasons it is at odds with the interest of the seed industry. Conventional plant breeding has thus ignored this opportunity. Theoretically it has argued that perennial grasses cannot be domesticated because they do not allocate sufficient energy for the development of large seeds; and politically it has been less plausible because of a rapid shift from public to private plant breeding (Price 1999). Nevertheless, a few visionary scholars started a still ongoing project to domesticate and breed perennial grains (Cox et al. 2006, Baker 2017). Doing so, they did not take the world as it is but went against not only theoretical conventional wisdom and the logic of dominant trends in plant breeding but also the interest of the seed industry. In case of success their findings will imply a fundamental socialecological change in and of agriculture.

\section{Problem solving and critical approaches in the social sciences}

The engagement of scientific reasoning to the understanding of social life and its problems can be traced back to the 14th century (e.g., Ibn Khaldun) and the classical Greeks (see McCarthy 2003). But for the purposes of this article the birth of modern sociology in the late 19th century is a good landmark for the analysis of science as a tool to solve social problems. Strongly inspired by positions such as Saint Simon's faith in science as a means to regenerate society (comte de Saint-Simon 1975), these early sociologists took a broad approach to social change. The methodological approach used by Auguste Comte and early sociologists was very similar to that used in the natural sciences but did not go uncriticized. Parts of Marx's work, for instance, were devoted to the critique of this perspective, its origins, and its social consequences (see McCarthy 1991). In a similar manner, other sociologists such as Durkheim, Weber, Tönnies, and Parssons, drew a sharp line between social and natural phenomena (see Ritzer and Stepnisky 2017). However, the dichotomies in these discussions went beyond the natural versus the social and included among others: empirical vs. theoretical, macro vs. micro, and qualitative vs. quantitative. By the end of the 1960s, social research was increasingly employed by governments and businesses alike. New types of social research methods were developed to deal with both new and old problems, but most of the above mentioned dichotomies still stay (and probably will stay) alive although shifting in importance. The growing political pressure to gear research toward practical goals in order to meet national or industrial needs defined by governments (see Hammersley 1995, Featherman and Vinovskis 2009) will push other dichotomies to the fore, such as applied vs. basic, or problem-solving vs critical. The political turn created conditions for an expansion of more pragmatic and problemcentered social research. However, soon and as a reaction to this problem-solving direction in the social sciences, new critical approaches emerged.

Critical theory starts from a meta-theoretical approach to knowledge and society, and thus provides guidelines for how to deal with ethical aspects, ideological dimensions, and political considerations in social research (Alvesson and Sköldberg 2017). Rooted in Marxism and inspired by socio-philosophical thinking, its mission is not only to understand the human condition in a social and historical context, but also to improve it, much like in development and sustainability science. Critical theory has both a narrow and a wider meaning in the social sciences. Originally associated with philosophers and social theorists in the Western European tradition of the Frankfurt school (Horkheimer, Adorno, Marcuse, Habermas), it broadened lately to include feminist theory, postdevelopment theory, race and postcolonial theory, and poststructural theories (Kincheloe and McLaren 2002).

Critical theory is concerned with how people are constrained by society. Starting from an understanding of politics that goes beyond government and state (Hay 2002) it aims at liberating people from all sorts of power relations (Hay 2002) and freeing them from repressive ideologies, institutions, and structures (Alvesson and Sköldberg 2017). In doing so, it seeks to identify social forces that circumscribe or prevent freedom; expose how we are constrained by ideas, interests, or institutions; and inform political action through explanation and meaning making (Denzin and Lincoln 2005). 
Following Habermas (1971), the role of (critical) research and researchers would be to influence political decisions, guide social processes, and/or initiate public processes of self-reflection. This could possibly also be the mission of problem-solving research. Researchers who explicitly apply a critical approach must consider the social and historical context and the practical character of social knowledge, thereby taking into account the preresearch knowledge that citizens and social agents already possess (see Bohman 2016). Following that perspective, the role of the researcher is neither to be an outside observer nor a full participant but to take a reflexive stance that allows criticism without claiming epistemic superiority (Bohman 2016). The researcher may start from a critical standpoint where s/he is informed by multiple theories and ideas about potential political pathways, policies, and programs while at the same time being open to empirical conditions and the diversity of needs in society (Alvesson and Sköldberg 2017).

To understand how values enter into and affect research requires reflexivity: how did we design and pursue research and what is our role and position in that process? According to critical theory, facts cannot be separated from values and facts are therefore not value neutral (May 2011). Also, the role of research is not first and foremost to discover or gather facts but to gain a profound understanding of society that can inform actions with a potential to change social reality (Ragin and Amoroso 2010). The role of theory and interpretation in critical theory is here to both diagnose and inform change (Wright 2010, May 2011). Again, as partially observed by $\mathrm{Cox}^{[1]}$ and as we ultimately claim, fruitful problem-solving social research is by nature critical. To exemplify, critical theory could help identify and locate conditions and processes of domination, inequality, oppression, subordination, or other forms of "un-freedom" (see Sen 1999). We can start by combining a normative with an empirical perspective, and seek to realize forms of democracy where none exist (Bohman 2016) or where democratic institutions are threatened, such as perhaps in illiberal democracy. In practice, we can try to combine a macrosociological view of society and social processes with a microsociological study of agents and their activities and cognition (Bohman 2016) such as done, for example, in field theory (see Olsson and Jerneck 2018 in this Special Feature). To refer back to our focus on sustainability we could diagnose agricultural modernization from a human-environmental perspective and then draw on Eric Olin Wright (2010) and his emancipatory social science to investigate the desirability, viability, and achievability of alternatives, such as agroecology (Isgren 2018). Or we could diagnose the use of biofuels in the transport sector and evaluate its desirability, viability, and achievability in relation to other alternatives (Harnesk 2018).

To sum up so far, we see that the divide between problem-solving and critical research is not clear-cut because its relevance is determined by the aim and nature of research. For those investigating broad issues such as the role of science in society, the distinction is almost always unavoidable, while for others dealing with, for instance, concrete issues such as the management of natural resources in a specific context, the distinction is rarely relevant. The analysis of the theses, starting below, will relate, directly or indirectly, to these debates while also paying special attention to how the tension between the two research modes can be resolved.

\section{THE ANALYSIS}

\section{Our method}

Departing from Cox (Cox 1981) we developed a template to analyze and categorize the 19 doctoral theses in our sample. Initially, we tested more of his terminology, including parts and whole, but in the end, we mainly found his use of concepts such as "ideas, institutions, material capabilities" and "frameworks for action" to be productive for describing and interpreting critical and problem-solving research in the field of sustainability. After reading the theses we agreed on how each thesis reflects the configurations in the template and to what extent it is problem solving and/or critical. We then enriched the selected concepts in the table through a closer reading of the theses and by relating them to core conceptual models in the interdisciplinary research program within which the theses emerged (see Jerneck et al. 2011). To advance the analysis further, we plotted the core ideas in each thesis against different dimensions of justice and pathways to sustainability (Figs. 3 and 4 in Jerneck et al. 2011) and then discussed how the theses cluster around certain dimensions illustrated by these figures. Based on the analysis we plotted the theses in the three-category-triangles illustrating the arguments of this article. Our approach will become clearer when we embark on the analysis.

\section{Theoretical starting points in sustainability research}

Although grand narratives and comprehensive theories may provide overall frameworks for critical analysis they do not necessarily ensure enough explanatory power for the phenomena we seek to understand (see Bohman 2016). For that we need middle-range theories to cover delineated empirical or social domains or aspects of social phenomena as well as methods and techniques that capture relevant types of material (Merton 1949). Hence, researchers in sustainability research who use, for example, a political ecology frame (Islar 2013, Krause 2013, Andersson 2014, Nastar 2014) or an emancipatory social science frame such as that inspired by Eric Olin Wright (Wright 2010, Harnesk 2018, Isgren 2018) need to engage with middle-range theories as do also those applying a multilevel framework (Geels 2010, Nastar 2014). This will (and need) to combine theories and methods is reflected in sustainability research and sustainability science (Shahadu 2016) where a typical research design could be a mixed-methods approach with a case study based on repeated on-site fieldwork involving document analysis, focus groups, interviews, narrative walks, observations, photos, and an array of participatory methods. The theoretical and methodological pluralism reveals in itself that the researcher recognizes the contingent character of the study object. In accepting reality as fluid rather than fixed, "critical theory must continually adjust its concepts to the changing object it seeks to understand and explain" (Cox 1981:129).

Rather than starting from one's own theoretical standpoint or perspective, one possible theoretical starting point in sustainability research is instead to take another's theoretical standpoint or practical activity as the point of departure. This approach, known as "immanent" (internal) critique is a method of argumentation and a foundation for knowledge claims that aligns well with critical realism and the idea that there is no neutral standpoint from which to ground knowledge claims (Isaksen 2018). Procedurally, one begins by taking a system of thought on 
its own terms and showing how it contains various internal contradictions in a particular way of thinking or acting. Once these are uncovered, more adequate ways of thinking and acting become necessary to overcome these inadequacies, thus providing the justification for theoretical and practical improvements. Immanent critique provides a method by which the internal connections between competing ideas can be established, and in doing so these ideas can be objectively organized along a continuum from least to most adequate in terms of their theoretical and practical coverage of a given sustainability challenge.

A recent example of the use of immanent critique in sustainability research comes from Boda (2018) who does a systematic assessment of competing coastal management techniques that have been proposed to solve persistent erosion problems in a small coastal community in the U.S. state of Florida. Eventually, in moving from critique to prescription, by applying immanent critique to the "best" idea currently on offer in the case study area, he is able to point toward novel solution strategies that could be rationally shown to overcome the residual tensions contained in the best idea on offer, thus providing constructive insights into how theorization and practical activity in the case context could be further improved.

\section{Methodology for studying social change}

The rational and final goal of both critical and problem-solving research is to transform reality, or at least some aspect of it, thus implying a direction and degree of social change, be it through incremental reform for increased diversity/redundancy or effectiveness, or through more radical social change such as emancipation, empowerment, or liberation. There can be differences in magnitude, scale, or time perspective, referring to how acute the problem is considered to be, or what it takes to understand, solve, or manage it. In pursuit of such social change, critical theory advocates interdisciplinary perspectives and a dialectic approach constantly combining theoretical reflection with empirical grounding (Ramsey 2000). This, again, speaks for pluralism in research and practice. If we propose that sustainability studies/science strive to combine critical with problem-solving research in various ways and degrees we also need to examine if and how that is done, and test it, as we do here on 19 purposefully selected theses from an interdisciplinary research program. Below we describe the specific steps in our analysis.

First, we asked if and how the theses explicitly address the problem-solving/critical theory "divide." We looked for how they understand and deal with the distinction, and if/how they align their work with one of the two approaches or in combination. Then we studied how they use critical theory to identify, what Cox considers to be the historical structures that determine the frameworks for action suggested, both in terms of limits and conditions. In their most abstract form these frameworks reflect the configuration of forces at a given time and space, expressed in ideas that are manifested in institutions and material capabilities. Below, we will show how this plays out. The dynamics of and the hierarchy within and among these forces are neither fixed, nor universal, nor independent of context. If social conditions are characterized by conflicting interests and various forms of asymmetrical power relations then social phenomena must be interpreted, explained, and challenged in their contemporary and historical context (Jones et al. 2011).

Thus, we explore how early career researchers examine sustainability in terms of ideas, institutions, and material conditions. For that we posed three core questions to the selected PhD theses: how do they identify, analyze, and challenge existing human-environmental power structures; where do they see potentials and mobilization for reform or transformation; and how do they understand change in relation to sustainability goals and transitions?

\section{Problem solving and critical perspectives in the theses}

To sum up the overall view of the 19 theses, we categorized four as problem solving, five as critical, and 10 as hybrids. To be sure, this distinction is not clear cut, but rather a matter of degree. Although some of the early career researchers were explicit about their approach, others were not. One author makes it clear by stating that the thesis "explores interactions between society and nature while seeking to combine critical thinking with problem solving research across academic disciplines" (Nastar 2014:8) and then argues that given her focus on water access in the Global South this can be done, by asking "how can we understand" urban water regimes and "what can be done" to tackle the unsustainable nature of their operations, especially in terms of inequality in water distribution (Nastar 2014:1). Another author, studying periurban dynamics in the Global South, has the ambition to "bridge the gap between problem-solving and critical research approaches" (Valencia 2016:24). She states explicitly that this will be done "by using concepts that can contribute to problemsolving, while taking a critical stand to understanding the socioeconomic and political structures that contribute to the constitution of uneven socio-environmental conditions" (Valencia 2016:24). Likewise, in another thesis, the combination is handled in a reflective way by stating: "I repeatedly thought about the usefulness and practical relevance of my work and how it might contribute both to critical understanding and, ultimately, to the solution of a particular social and environmental problem" (Krause 2013:25). The aim in this particular thesis was to provide a critical discussion on enclosure (and the rights of indigenous people) while being problem solving in terms of examining (and developing) market based instruments for forest conservation that include animal species conservation and participatory forest monitoring (Krause 2013).

Most of the research in the selected doctoral theses clearly exemplifies aspects that are central to critical approaches in the construction of scientific narratives. This is seen in how they deal with a particular sustainability challenge such as biodiversity loss, climate change, land-use change, soil degradation or water scarcity, all representing core sustainability challenges. Oftentimes, they do so in relation to distributional issues, be it economic fairness, environmental justice, or social inclusion. We also found that those who are both critical and problem solving more often than not address two sustainability challenges simultaneously such as, for example, water scarcity in the context of climate change or biodiversity loss due to processes of land use change. Further, they address these challenges in the context of persistent social problems such as, for example, social exclusion, poverty, inequality, or marginalization, thus operating at the nexus of new sustainability challenges and old social problems (Figure 1 in Jerneck et al. 2011). 


\section{On critical theory and political ecology}

As argued above, critical perspectives tend to adhere to one of many (older) critical theories in the scientific community or to newer forms of critical theory that have emerged to deal with social relations of capitalism, colonialism, racism, or sexism. Each form comes with its own social aims, language, and priorities. Neo-Marxism would seek to end unequal exchange between center and periphery, postcolonial theory would speak in terms of ending Western hegemony, antiracism would seek ways to end discrimination, and feminism would seek ways to end patriarchy. One of the more recent critical theories, political ecology, would speak in terms of ending local and context specific unequal resource exploitation and, in extension, the ecological debt to the Global South (Warlenius 2017). Political ecology advocates complex analyses of how politics, human agency, and discourses influence both human-environmental interaction and natural resource control and management.

Most of the selected theses, especially those in sustainability science, apply political ecology. Their motivations are the following: "It is known for taking a critical predisposition, where specific urban environmental problems are linked to larger socioeconomic and environmental processes through uneven power relations" (Valencia 2016:23). It can also address global-to-local power dynamics in the search and test of institutional arrangements (such as market instruments) that can potentially promote forest conservation and rural development but which, at the same time, also cause problems in a geographical area with clashing economic and political interests (Krause 2013). Moreover, it can be used to problematize local agricultural development in relation to dominant global food regimes (Andersson 2014).

Political ecology is often used as an overarching umbrella frame that guides "the query and reframing of accepted environmental narratives ... directed via international environment and development discourse" (Islar 2013:33). In the theses it is common, as mentioned above, to supplement it with other theories and concepts often, but not always, originating in or, again, associated with critical theory. A political ecology frame can thus also be combined with theories and concepts associated with mainstream development or sustainability discourses such as capabilities, vulnerability, well-being, etc. (Valencia 2016).

One common way to fulfill the dual critical and problem-solving aim seems to be to start from an overall critical frame to be elaborated with (further) critical theory (feminism, Marxism, socio-nature, etc.) or concepts, often associated with development or sustainability, while at the same time, adhering to a problemsolving orientation that seeks to advance specific solutions to the problem in focus. This fits well with both constructivist (Islar 2013, Hansen 2014, Ramasar 2014) and critical realist perspectives (Krause 2013, Nastar 2014, Valencia 2016) often used in the examined theses.

Next, we will explore if, how, and to what extent the theses are problem-solving. We will also examine if they adhere to critical theory and, as would be expected then, how they study relevant historical structures and power relations. We follow Cox's distinction and seek out ideas, institutions, and material conditions that the authors have identified as relevant in their research.

\section{Ideas and institutions}

Besides the omnipresence of sustainable development and sustainability, we found that the theses mainly congregate around the core ideas of conservation, environmental justice, food security, gender equality, power, and resource distribution. Several of those issues relate to dimensions of international, intergenerational, and intersectional justice (see Fig. 3 in Jerneck et al. 2011) and some authors speak of those in terms of equality, fairness, and well-being.

We found that all the selected theses address formal or informal institutions such as norms, rules, values, or ritualized practices and conventions that are located anywhere from the global to the local. To exemplify along the line of scales, they focus on the global institutionalization of capitalism; national institutional arrangements for energy provision, climate governance, environmental governance, water governance, or public-private partnerships; regional institutional arrangements for decarbonization, trade or transports; or local institutional conditions for city planning, grain banks, labor markets, municipal networks, soil improvement, or water provision. Few theses are limited to one scale and, as is typical in sustainability science and sustainability studies, many studies are multiscalar. This is exemplified by one thesis analyzing how global-to-national-to-regional top-down processes drive protected area conservation and heritage status, while studied bottom-up processes focus on everyday livelihoods, individual agency, and collective resistance (Hansen 2014).

However, and to sum up here, we realize that the analysis of ideas and institutions is not sufficient for discerning whether a thesis has a mainly critical or problem solving approach. This takes us to the next step.

\section{Material capabilities}

In the move from idea to materiality we analyzed and categorized the 19 theses based on how they speak of material capabilities. From that, we distilled three main types oriented toward knowledge, natural resources, and organizational capacity (see Fig. 1).

Fig. 1. Three major aspects of material capabilities.

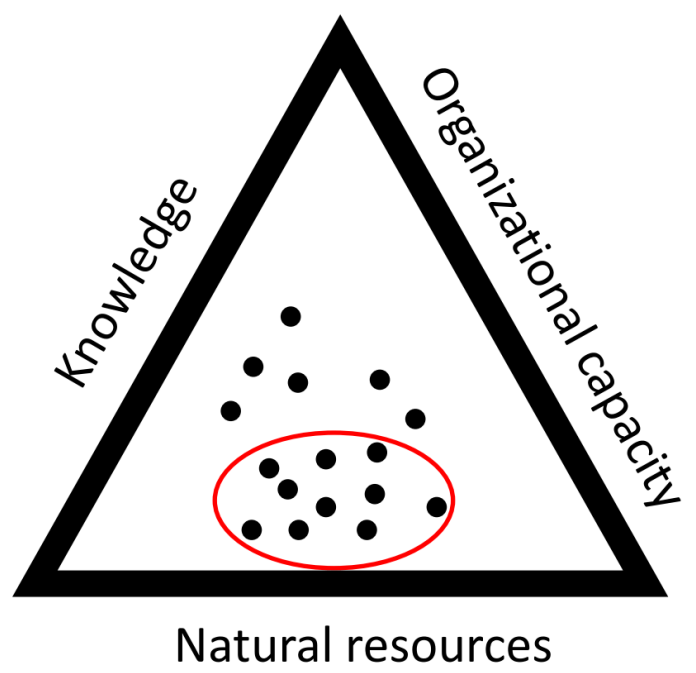


In the knowledge type, we include local knowledge, science, and technology; in organizational capacity we include the performance of agencies, corporations, governments, and networks; and in natural resources we include those resources that are associated with biodiversity, land, and water, all of which are directly related to sustainability challenges (Jerneck et al. 2011). Interestingly, we noted that research oriented toward problem solving tends to cluster along the upper sides of the triangle where knowledge meets organizational capacity, whereas the theses that combine critical with problem-solving research tend to be more materially focused given that they are more explicitly driven by a sustainability challenge (König 2018). Hence, they engage with natural resources such as forests, land, soils, water, or several of those in combination while also addressing the two other aspects of the triangle. Configuratively they tend to cluster at the bottom of the triangle, or toward the middle if they also address knowledge and organizational capacity as equally.

\section{Combining ideas, institutions, and material capabilities in research narratives}

Below we offer three examples of how a thesis in our sample may weave ideas, institutions, and material capabilities into a sustainability narrative. At the same time, each of the three shows how the researcher seeks to integrate critical theory with problemsolving approaches by navigating between sustainability challenges, persistent social problems, and complex social relations of power. By being concerned with justice and power, as in critical theory (Denzin and Lincoln 2005) they consider social facts "from the point of view of variously situated agents" (Bohman 2016). As illustrated below, that analytical process is facilitated by a series of dialectical and heuristic moves (Abbott 2004).

In her critical analysis, Cheryl Sjöström (2015) centers on the global food system as an entry point, using the idea of food security for smallholder farmers as the core of her analysis, and the Millennium Villages Project as an idealized form of assistance to eradicate poverty, first locally, and then globally. She reveals the different forces involved in shaping the global discourse on food insecurity and identifies the strategies they suggest as a remedy (Sjöström 2015). By closely studying how influential organizations such as the World Bank, the Earth Institute with its Millennium Villages Project, and the World Economic Forum contribute to the discourse on "smallholder farm food insecurity" she uncovers how their ideological and interest-based perspective make them blind to the complexities of the issue. Further, and as an expression of power, she shows that smallholder farmers who produce food for a living and who suffer from hunger and food insecurity are the least influential in shaping the discourse and the strategies it engenders. As regards material capabilities, Sjöström emphasizes the central role of knowledge. She suggests a critical reading of the entire discourse, and salutes alternative discourses around food, food security, and valuation systems of agriculture, whereby the role of power is recognized and embraced as part of social movements seeking the liberation and autonomy of smallholders and the valuation of the biophysical basis of food production as a means to repair and rebuild the food system (Sjöström 2015).

In a similar manner as above, Wim Carton (2016) focuses on the commodification of carbon and uses three policy instruments (the
EU Emissions Trading Scheme, the Flemish Tradable Green Certificate scheme, and Trees for Global Benefits) to elucidate structural explanations to the specific environmental outcomes engendered by market-based climate and energy policy. By recognizing the intricate ways in which social and environmental sustainability are interlinked, he suggests that democratic solutions may in fact entail increased environmental degradation while market-based policies may bring some sort of environmental gains even if they remain socially unjust. Following a long-standing critical tradition situated in a historical materialist philosophy and drawing on Marx, Carton concludes that social and political choices are always made under circumstances inherited from the past, thus indicating some degree of path dependence. The only way to understand why weak climate and energy policies persist is therefore to pay attention to the dynamics of capital accumulation that are materialized in the contemporary social-ecological landscape. According to him, reducing carbon's use-value to a singularity accounting for greenhouse gas emissions transforms the deep social, environmental, and economic crisis we are facing into "a technological problem" that can be managed by "end-of-pipe solutions" (Carton 2016:81), something that will not necessarily bring about sustainability, he argues.

In her thesis on water governance in South Africa, and as our third example, Vasna Ramasar (2014) examines how the politics of scaling can be used to manipulate water access and allocation to the benefit of some social actors at the cost of others. Like Carton above, on carbon commodification, she argues that the hydrosocial landscape is constantly shaped by ecological, economic, and political forces at the nature-society nexus. By studying three formal government decisions (the approval of the construction of the De Hoop Dam, the water service delivery mechanisms in Johannesburg, and the decision to explore hydraulic fracturing in the Karoo) Ramasar shows that in the processes of scaling and rescaling ${ }^{[2]}$, governments and elites succeed in disempowering other actors. For instance, the need for jobs can be perverted to push through projects that lead to socialecological injustices for communities living close to dams as well as for those who are downstream water users. Water as an economic good, she claims, triumphs over water as a human right. From her three selected cases, she concludes that historical patterns of privilege and disadvantage are perpetuated through processes of scaling that jeopardize environmental justice.

As just noticed, it is common in an analysis of humanenvironmental interaction to focus on struggles over resource distribution or conflicts around recognition and representation (Fraser 2010a, b) many of which may be associated with sustainability challenges and responses to those, thus often associated with both critical thinking and a solutions orientation. Typical examples would be the resistance against a certain private or public initiative, mechanism or policy pertaining to a particular natural resource, be it a dam, a forest, a land area, a natural reserve, a river, or a public utility such as water. The conflict at hand is often reflected in (and supported by) specific ideas and institutions, such as environmental discourse, legislation, or certain interpretations of the constitution. The role of a thesis in sustainability research engaging with critical theory is thus often to locate the tension between different interests, to identify the contradictions in governance and planning, to uncover power 
asymmetries in the process of reaching social goals, and to understand what is at stake in a particular human-environmental interaction, often involving multiscalar interests. To take an example from the Global South, Melissa Hansen (Hansen 2014:5) in her case on the iSimangaliso Wetland Park in South Africa, studies both distributive and procedural justice when she "interrogates conflicts over conservation space between conservation authorities, and local users and inhabitants," and does so to "provide a more nuanced recognition of the relationship between human and non-human nature." Given that the park is designated by UNESCO as a world heritage site, it also has multiple global to national to local implications.

Like many others, sustainability researchers seek to signal the core message of their work in the thesis title, which, in this case, often alludes to human-environmental dynamics and sustainability conflicts, as seen in Private Rivers (Islar 2013), Buying Conservation (Krause 2013), Struggles over Conservation Space (Hansen 2014), Caught between Spaces (Valencia 2016), and Fictitious Carbon, Fictitious Change (Carton 2016). Also, subtitles allude to that tension, such as Territorial Hunger (Jönsson 2013), The Rise of Water Struggles in Turkey (Islar 2013), The Politics of Environmental Discourse (Bettini 2013), The Politics of Food in Agricultural Modernization (Sjöström 2015), An Analysis of How Urban Water Regimes in the Global South Reproduce Inequality (Nastar 2014), and Scalar Politics in the South African Waterscape (Ramasar 2014).

To refer back to critical theory, and based on how it is applied in critical approaches above, it is now safe to argue that researchers will use it to reveal subtle forms of social dominance, and to question taken-for-granted assumptions by being skeptical against claims of truth; by recognizing the influence of culture, history, and social position; and by imagining alternatives that destabilize routines and the established order (Alvesson and Sköldberg 2017).

\section{On responses to sustainability challenges}

Theory is a way to think abstractly about the world and to speak of it in particular vocabularies. Whereas some see theory as a way to understand and give meaning to things, others see it as an evidence-supported explanation of how things operate and interact (and can become more efficient). Others again, see it as a way to critique and change social reality. If we believe that social life, and even more so human-environment interaction, is not only diverse but also dynamic and complicated, it cannot be explained by only one type of theory. As already observed by Giambattista Vico in the 18th century, the nature of human institutions "should not be thought of in terms of unchanging substances but rather as a continuing creation of new forms" (Cox 1981:132).

The advantage of the problem-solving perspective lies in its ability to reduce research objects to a limited number of variables that can be relatively easy to examine. However, this relative strength rests, oftentimes, upon the false premise that social and political orders are fixed. This assumption is not simply a convenience of method, but an obvious, but often implicit, ideological bias. Problem-solving theories can thus "be represented, in the broader perspective of critical theory, as serving particular national, sectional, or class interests, which are comfortable within the given order" (Cox 1981:129, emphasis added). Thus, one must be aware that what may look like a solution to a degrading environment may instead be a way to maintain a specific social and economic order. In other words, a solution overloaded with political tensions.

At this point, we realize that critical approaches can help pointing out the direction of change and suggest how to change socially and historically constructed conditions toward a particular purpose such as emancipation, empowerment, equality, environmental justice, food security, etc. Finally, we will therefore look at how the theses envision change and how they express the potential for transformation as a key ambition in critical theory, or partial solutions to social change as in problem-solving perspectives.

By being both explanatory and normative, critical theory is equally appropriate for generating empirical descriptions of social context as for suggesting "a practical proposal for social change" (Bohman 2016). To serve its normative and prescriptive purposes, critical theory has an interest in critically scrutinizing and disputing social realities. It does so by taking a dialogic and interpretivist approach to knowledge and knowledge production, or what some may call critical hermeneutics and deliberative discourses (Cox 1981, Denzin and Lincoln 2005). In consequence, we expect critical theory to focus not only on what is but also on what could be thus helping researchers and citizens imagine new ways to "ease human suffering and produce psychological health" (Denzin and Lincoln 2005:308). By applying the methodological tools of deconstructing, decolonizing, or unveiling a research object, critical theory seeks to unmask current conditions and produce fundamental insights and findings that hold the seeds of transformative action (Denzin and Lincoln 2005). In a sustainability context, where the analysis should integrate natural aspects that are independent of power relations, this could be translated to envisioning and imagining more environmentally just and sustainable futures.

In the interdisciplinary research program under scrutiny here, researchers suggested three common types of responses to and modes of governing sustainability challenges that can be used to solve a particular problem: democratization, marketization, and regulation (Jerneck et al. 2011). In the content analysis of the theses, we found that 14 of the 19 theses in our sample relate to one or more of those three responses.

The democratization pathway is often associated with and connected to various forms of collective action. This is often seen by highlighting social mobilization and the importance of vitalizing democratic processes, for example on the basis of alternative knowledge and understandings. Several theses advocate inclusionary politics and do so by applying, or tending to apply, a bottom-up perspective on democracy specified, for example through contentious politics (McAdam et al. 2003, Nastar 2014) or decommodification. The theses that focus on regulation often study and refer to specific policies on conservation, decarbonization, or ownership and property rights. The theses that are concerned more broadly with the inclusion of civil society and social movements in governance and in regulation, often combine elements of regulation and democratization. No thesis dealt strictly with marketization. Rather, if present it was combined with regulation, for example by addressing public-private partnerships, property rights or voluntary certification. Two theses combine all three processes. 
One does so through an agency for autonomy perspective, as seen from the point of view of grass-roots in Hansen's case of conservation where strong top-down global-to-national initiatives are met with strong local bottom-up resistance as a reaction against the violation of local norms and rights (Hansen 2014). The other does so through an analysis of the conditions for a decarbonized society addressing not only regulation and marketization but also democratization (Carton 2016).

Both critical theory and problem-solving approaches aim at some type of change ranging from more adaptive or incremental responses to more profound and transformative social change. Interestingly, we observed that many theses have a tendency to refer to social rather than integrated human-environmental change, and many of them do not necessarily problematize the natural resource they engage with from a natural scientific perspective. We argue here that a deeper understanding of the natural resource or environmental condition in question might lead to new and innovative framings, such as the previously given example on the domestication and breed of perennial grains. Innovative framings have oftentimes the capacity to turn the source of a problem into the basis for solutions, such as in the case of turning waste (human urine) into value (fertilizers) in the context of sub-Saharan small-scale agriculture (Andersson 2014). Such reframing is an illustration of what Andrew Abbott calls methods of discovery (Abbott 2004) through the use of a variety of heuristics that can help frame and reframe a problem.

In terms of how to approach and perceive social change, we noted that the authors tended to think in terms of effectiveness, redundancy/diversity, or deeper social transformation as illustrated in Figure 2. Further, we found that transformation, which in itself is a major fundamental process implying both institutional and ideational change (Geels 2010, Granovetter 2017), is more often associated with a critical approach in the theses. In contrast, effectiveness evokes a process of adjustment and change within society as it is, rather than profound change, and is more often associated with increased efficiency within existing social structures. Such change was mainly associated with the theses leaning toward a problem-solving aim (Lund 2013, Hildingsson 2014, Busch 2016). In the multiple calls for resilience it is necessary to allow for or, build in, some redundancy (Low et al. 2002), and when the very existence of specific ecosystems is threatened it is necessary to take (social) diversity into account in the call for increased sustainability. Hence, we included redundancy and diversity along one leg. Below, and based on our analysis, we illustrate different pathways to change.

In sum, and unsurprisingly, the theses fitting the problem-solving category tend to cluster at the top of the triangle between effectiveness and redundancy/diversity, while those that are critically oriented tend to crowd along the base, of transformation, or cluster in the middle if they also address effectiveness and redundancy/diversity. Interestingly, a certain group of theses that succeeded well in integrating problem-solving and critical approaches, tends to cluster in the middle and toward the bottom of the triangle.

\section{CONCLUSIONS AND IMPLICATIONS}

The outcome of this exercise illustrates three things. First it shows that all the analyzed theses fulfill the ambition to combine problem-solving and critical approaches, albeit in varying degrees and in varying ways. Second, it shows that empirical experiences of sustainability challenges are multifaceted, and that analytical understandings are interrelated across various theoretical and methodological dimensions and along varying trajectories of social continuity and change. In more detail, it shows how different dimensions of environmental justice relate to various types of social capabilities and material resources and how, in the vocabulary used by Cox, frameworks for action develop to match those dimensions, either to address (or even solve) a particular problem or critically approach certain unsustainable conditions in society, or both. Third, and more importantly, the clustering shows how a certain group of theses succeeds particularly well in integrating the "two cross-cutting approaches" of critical and problem-solving research (Jerneck et al. 2011:73). Based on that, we suggest some criteria for how to position research that aims to strengthen the potential of achieving a feasible combination of the two.

Fig. 2. Three pathways toward sustainability indicating the direction of desired change.

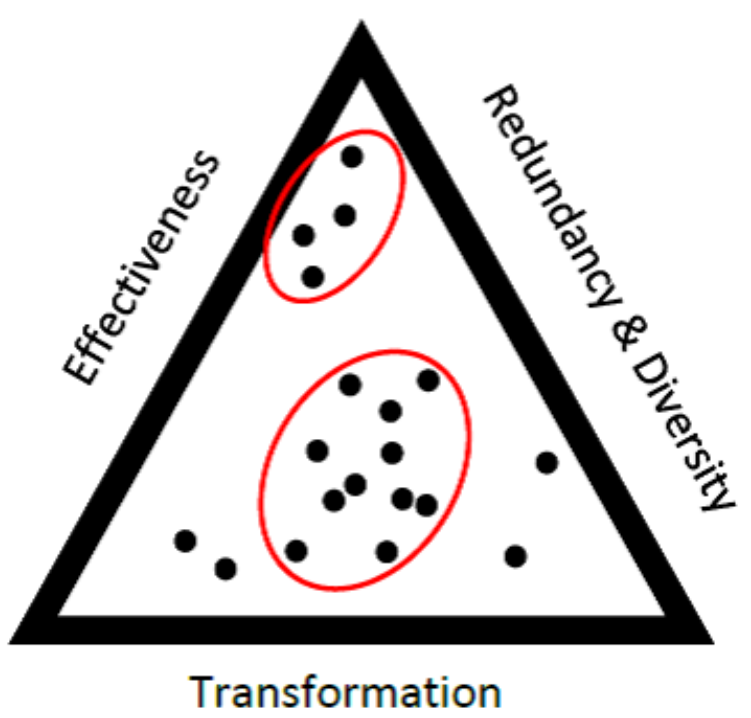

Multiscalar approaches and emergence

We emphasize that a critical problem-solving analysis in sustainability research should be empirically grounded in humanenvironmental realities while taking the causal and constitutive influence of ideas and discourse into account (Hay 2002). With strong awareness of the role of space and time as well as the dynamics of agency and structure, it should consider the local in relation to the global (to be defined in each case) and be open to contingency and emergence. Further, it should show the consequences of scalar analysis. This means that positive solutions and benefits arising from a purely local analysis may not be optimal (or can even be detrimental) at other scales. For instance, Ramasar's reflections on the use of scale as a means to favor some interests over others is an illustration of this condition (Ramasar 2014) and so is Carton's argument that democracy does not always guarantee environmentally sound decisions (Carton 2016). Linking back to Cox (1981) we can state that the concept 
of scale was hardly developed as an analytical tool: "the integration of production processes on a transnational scale ... currently plays the formative role in relation to the structure of states and world order that national manufacturing and commercial capital played in the mid-Nineteenth century" (Cox 1981:146).

\section{Theoretical and methodological pluralism}

As an interdisciplinary or even transdisciplinary field of research on human-environment interaction, sustainability research, and especially sustainability science, embrace theoretical and methodological pluralism rather than unification (Thorén 2015). Given the complexity of modernity it can be argued that both science and reality will benefit from explanations, interpretations, and meanings rooted in different and complementary or even competing theories and methods. As a whole, interpretations generated via different lenses may contribute a fuller picture of a complex reality in need of transitions toward sustainability. In the political sense, this pluralism may act as a guarantor of a wider inclusion of human-environmental interests and perspectives that affect and are affected by the sustainability challenges in focus here (see also Olsson and Jerneck 2018 in this Special Feature).

\section{Social theory for human-environmental change}

It is fruitful in sustainability studies, to take a critical realists or a constructivist position, both of which seem to equally well serve the purpose of combining critical with problem solving research. The ambition to integrate social and natural dimensions of sustainability benefits from a consistent, yet creative, use of social theory as a "guide to the social sphere" that devises questions and strategies to explore it (Denzin and Lincoln 2005:306), and in extension also change it. Social change can here be defined as a problem-solving attempt to search for "possible practical perspectives that knowledgeable and reflective social agents are capable of taking up and employing practically in their social activity" (Bohman 2016).

In most cases, we find that the distinction between problemsolving and critical theory is useful. As correctly observed by Cox, problem-solving approaches try to deal with particular sources of trouble without calling into question the social relationships and institutions where these arise. In contrast, critical theory does not take either the institutions nor ideas or power relations for granted. Quite the opposite, it calls them into question to the point of requiring their transformation or even elimination (Cox 1981).

In this article, we have shown how the analytical elements that we were inspired to adopt from Cox (1981) and then searched for in our investigation are present in the empirical material that we examined. Based on that it is safe to conclude that the research school in sustainability research, that was the object of our study, contributed critical perspectives and social science theory to the endeavor of understanding and tackling sustainability challenges while also addressing the issue of finding and formulating solutions to the problems created in their wake. In all, this is a contribution to sustainability research that we hope will serve as an inspiration for others. In striving to do critical problem-solving research we suggest that researchers aim to position their work toward the middle of the triangle (Fig. 3).
Fig. 3. Three characteristics of critical problem-solving theses in sustainability studies.

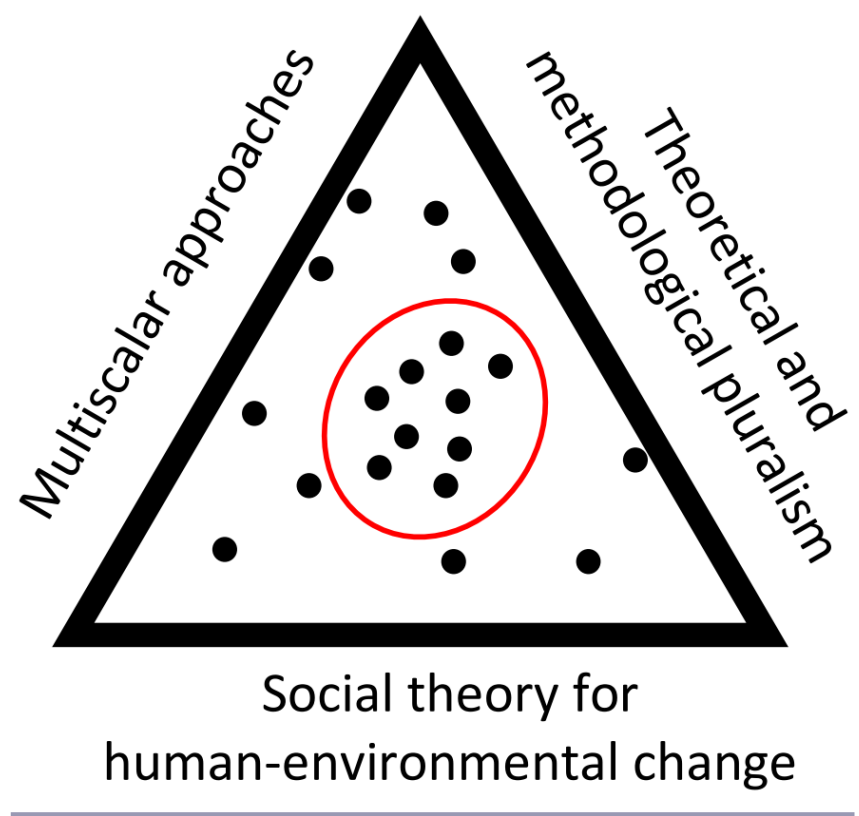

Social and natural science theory for human-environmental change

Beyond that, what is now the way forward? We suggest that researchers with a leaning toward social aspect of sustainability also engage ambitiously with natural science aspects of humanenvironmental dynamics, as done by some in our sample (Krause 2013, Yengoh 2013) and by others in more recent theses in the interdisciplinary research program (Boda 2018, Isgren 2018). Only then, will we be able to reach a fuller understanding of the social and the natural dimensions of sustainability based on the best available knowledge from both the social and the natural sciences.

[1] "Critical theory is, of course, not unconcerned with the problems of the real world. Its aims are just as practical as those of problem-solving theory, but it approaches practice from a perspective which transcends that of the existing order, which problem-solving theory takes as its starting point" (Cox 1981:130).

${ }^{\text {[2] }}$ Scale is a highly disputed concept, but in this context it can be understood as a political outcome emanating from power interactions, specific material processes, and concrete forms of agency. In this sense, scaling and rescaling are the processes through which the modes of governance and regulation involve states and civil societies and their influence on spatial relations are established.

\section{AUTHOR CONTRIBUTIONS}

Proceeding from the ideas presented in Jerneck et al. 2011, Annica Kronsell initiated the article. Yahia Mahmoud structured the 
analysis of the $\mathrm{PhD}$ theses. All authors contributed to the analysis of the theses while Karin Steen took the lead in illustrating it. Yahia Mahmoud and Anne Jerneck took the lead in writing the article. All authors contributed to and commented on the text.

Responses to this article can be read online at: http://www.ecologyandsociety.org/issues/responses. $\mathrm{php} / 10458$

\begin{abstract}
Acknowledgments:
The research was undertaken within the interdisciplinary LUCID project (2008-2018) funded by the Swedish Research Council Formas through the Linnaeus grants: Lund University Centre of Excellence for integration of Social and Natural Dimensions of Sustainability (LUCID) (259-2008-1718). We are grateful to LUCID colleagues who commented on early ideas developed in this article and we would like to thank those who commented on earlier versions of this manuscript, especially Chad Boda and Lennart Olsson. We also appreciate constructive critique from two anonymous reviewers.
\end{abstract}

\section{LITERATURE CITED}

Abbott, A. 2004. Methods of discovery: heuristics for the social sciences. Contemporary Societies series. W.W. Norton \& Company, New York, New York, USA.

Agre, G. P. 1982. The concept of problem. Educational Studies 13:121-142. http://dx.doi.org/10.1207/s15326993es1302_1

Alvesson, M., and K. Sköldberg. 2017. Reflexive methodology: new vistas for qualitative research. Sage, London, UK.

Andersson, E. 2014. Fertile grounds? Collective strategies and the political ecology of soil management in Uganda. Dissertation. Faculty of Social Sciences, Lund University, Lund, Sweden.

Baker, B. 2017. Can modern agriculture be sustainable? Perennial polyculture holds promise. BioScience 67:325-331. http://dx.doi. org/10.1093/biosci/bix018

Bettini, G. 2013. Climatised moves-climate-induced migration and the politics of environmental discourse. Dissertation. LUCSUS, Lund University, Lund, Sweden.

Boda, C. 2018. The beach beneath the road: sustainable coastal development beyond governance and economics. Dissertation. LUCSUS, Lund University, Lund, Sweden.

Bohman, J. 2016. Critical theory. In E. N. Zalta, editor. The Stanford encyclopedia of philosophy. Metaphysics Research Lab, Stanford University, Palo Alto, California, USA.

Brincat, S. 2016. Traditional, problem-solving and critical theory: an analysis of Horkheimer and Cox's setting of the 'critical' divide. Globalizations 13:563-577. http://dx.doi.org/10.1080/14747731.2015.1130204

Busch, H. 2016. Entangled cities: transnational municipal climate networks and urban governance. Dissertation. LUCSUS, Lund University, Lund, Sweden.
Carton, W. 2016. Fictitious carbon, fictitious change?: Environmental implications of the commodification of carbon. Dissertation. Faculty of Social Sciences, Lund University, Lund, Sweden.

comte de Saint-Simon, H. 1975. Henri Saint-Simon (1760-1825): selected writings on science, industry, and social organisation. Taylor \& Francis, Abingdon, UK.

Cox, R. W. 1981. Social forces, states and world orders: beyond international relations theory. Millennium 10:126-155.

Cox, T. S., J. D. Glover, D. L. Van Tassel, C. M. Cox, and L. R. DeHaan. 2006. Prospects for developing perennial grain crops. BioScience 56(8):649-659. http://dx.doi.org/10.1641/0006-3568 (2006) 56[649:PFDPGC]2.0.CO:2

Crews, T., T. Cox, L. DeHaan, S. Damaraju, W. Jackson, P. Nabukalu, D. Van Tassel, and S. Wang. 2014. New roots for ecological intensification. Crops, Soils, Agronomy News 59:16-17. http://dx.doi.org/10.2134/csa2014-59-11-7

Denzin, N. K., and Y. S. Lincoln. 2005. Introduction: the discipline and practice of qualitative research. Chapter 1 in N. K. Denzin, and Y. S. Lincoln, editors. The SAGE handbook of qualitative research. Sage, Thousand Oaks, California, USA.

Featherman, D. L., and M. A. Vinovskis. 2009. Social science and policy-making: a search for relevance in the twentieth century. University of Michigan Press, Ann Arbor, Michigan, USA. http:// dx.doi.org/10.3998/mpub.11362

Foucault, M. 2012. The archaeology of knowledge. Routledge, London, UK.

Fraser, N. 2010a. Injustice at intersecting scales: on 'social exclusion' and the 'global poor.' European Journal of Social Theory 13(3):363-371. http://dx.doi.org/10.1177/1368431010371758

Fraser, N. 2010b. Who counts? Dilemmas of justice in a postwestphalian world. Antipode 41:281-297. http://dx.doi. org/10.1111/j.1467-8330.2009.00726.x

Geels, F. W. 2010. Ontologies, socio-technical transitions (to sustainability), and the multi-level perspective. Research Policy 39:495-510. http://dx.doi.org/10.1016/j.respol.2010.01.022

Gherardi, S., and B. Turner. 2002. Real men don't collect soft data. Pages 81-100 in A. M. Huberman and M. B. Miles, editors. The qualitative researcher's companion. Sage, Thousand Oaks, California, USA.

Granovetter, M. 2017. Society and economy: framework and principles. Harvard University Press, Cambridge, Massachusetts, USA. http://dx.doi.org/10.4159/9780674977792

Habermas, J. 1971. Toward a rational society. Heinemann, London, UK.

Habermas, J., and S. Ben-Habib. 1981. Modernity versus postmodernity. New German Critique 22:3-14. http://dx.doi. org/10.2307/487859

Hammersley, M. 1995. The politics of social research. Sage, Thousand Oaks, California, USA. 
Hansen, M. 2014. Struggles over conservation space: social justice in the iSimangaliso Wetland Park, South Africa. Dissertation. Faculty of Social Sciences, Lund University, Lund, Sweden.

Harnesk, D. 2018. Adding fuel to the fire. Dissertation. LUCSUS, Lund University, Lund, Sweden.

Hay, C. 2002. Political analysis: a critical introduction. Palgrave Macmillan, London, UK. http://dx.doi.org/10.1007/978-0-230-62911-0

Hildingsson, R. 2014. Governing decarbonisation: the state and the new politics of climate change. Dissertation. Department of Political Science, Lund University, Lund, Sweden.

Horkheimer, M. 1972. Critical theory: selectedessays. Vol. 1. A\&C Black, London, UK.

Isaksen, K. R. 2018. Without foundation or neutral standpoint: using immanent critique to guide a literature review. Journal of Critical Realism 17(2):97-117. http://dx.doi.org/10.1080/147674$\underline{30.2018 .1427180}$

Isgren, E. 2018. Between nature and modernity: agroecology as an alternative development pathway. Dissertation, LUCSUS, Lund University, Lund, Sweden.

Islar, M. 2013. Private rivers: politics of renewable energy and the rise of water struggles in Turkey. Dissertation, LUCSUS, Lund University, Lund, Sweden.

Jerneck, A., L. Olsson, B. Ness, S. Anderberg, M. Baier, E. Clark, T. Hickler, A. Hornborg, A. Kronsell, E. Lövbrand, and J. Persson. 2011. Structuring sustainability science. Sustainability Science 6:69-82. http://dx.doi.org/10.1007/s11625-010-0117-x

Jones, P., L. Bradbury, and S. LeBoutillier. 2011. Introducing social theory. Polity, Cambridge, UK.

Joseph, J. 2013. Resilience as embedded neoliberalism: a governmentality approach. Resilience 1(1):38-52. http://dx.doi. org/10.1080/21693293.2013.765741

Jönsson, E. 2013. Fields of green and gold: territorial hunger, rural planning, and the political ecologies of high-end golf. Dissertation. Department of Human Geography, Lund University, Lund, Sweden.

Khagram, S., K. A. Nicholas, D. M. Bever, J. Warren, E. H. Richards, K. Oleson, J. Kitzes, R. Katz, R. Hwang, R. Goldman, J. Funk, and K. A. Brauman. 2010. Thinking about knowing: conceptual foundations for interdisciplinary environmental research. Environmental Conservation 37:388-397. http://dx.doi. org/10.1017/S0376892910000809

Kincheloe, J. L., and P. McLaren. 2002. Rethinking critical theory and qualitative research. Pages 87-138 in Y. Zou and E. T. Trueba, editors. Ethnography and schools: Qualitative approaches to the study of education. Rowman \& Littlefield, Lanham, Maryland, USA.

König, A. 2018. Sustainability science as a transformative social learning process. Pages 3-28 in A. König, editor. Sustainability science: key issues. Routledge, Abingdon, UK. http://dx.doi. org/10.9774/GLEAF.9781315620329 2

Krause, T. 2013. Buying conservation-financial incentives for tropical forest conservation in the Ecuadorian Amazon. Dissertation, LUCSUS, Lund University, Lund, Sweden.
Kuhn, T. S. 1962. The structure of scientific revolutions. University of Chicago Press, Chicago, Illinois, USA.

Low, B., E. Ostrom, C. Simon, and J. Wilson. 2002. Redundancy and diversity: do they influence optimal management. Pages 83-114 in F. Berkes, J. Colding, and C. Folke, editors. Navigating social-ecological systems: building resilience for complexity and change. Cambridge University Press, Cambridge, UK. http://dx. doi.org/10.1017/CBO9780511541957.007

Lund, E. 2013. Hybrid governance in practice-public and private actors in the Kyoto Protocol's clean development mechanism. Dissertation. Department of Political Science, Lund University, Lund, Sweden.

Lyotard, J.-F. 1984. The postmodern condition: a report on knowledge. University of Minnesota Press, Minneapolis, Minnesota. USA.

May, T. 2011. Social research: issues, methods and process. Fourth edition. Open University/McGraw-Hill Education, Berkshire, UK.

McAdam, D., S. Tarrow, and C. Tilly. 2003. Dynamics of contention. Social Movement Studies 2:99-102. http://dx.doi. org/10.1080/14742837.2003.10035370

McCarthy, G. E. 1991. Marx's critique of science and positivism. Springer, Dordrecht, The Netherlands.

McCarthy, G. E. 2003. Classical horizons: the origins of sociology in ancient Greece. SUNY Press, Albany, New York, USA.

Merton, R. K. 1949. On sociological theories of the middle range. The Free Press, New York, New York, USA.

Morin, E. 1992. From the concept of system to the paradigm of complexity. Journal of Social and Evolutionary Systems 15:371-385. http://dx.doi.org/10.1016/1061-7361(92)90024-8

Moses, J. W., and T. L. Knutsen. 2012. Ways of knowing: competing methodologies in social and political research. Palgrave Macmillan, Basingstoke, UK.

Nastar, M. 2014. Navigating troubled waters. An analysis of how urban water regimes in the global South reproduce inequality. Dissertation. LUCSUS, Lund University, Lund, Sweden.

Olsson, L., and A. Jerneck. 2018. Social fields and natural systems: integrating knowledge about society and nature. Ecology and Society 23(3):26. https://doi.org/10.5751/ES-10333-230326

Olsson, L., A. Jerneck, H. Thoren, J. Persson, and D. O’Byrne. 2015. Why resilience is unappealing to social science: theoretical and empirical investigations of the scientific use of resilience. Science Advances 1(4):e1400217.

Price, S. C. 1999. Public and private plant breeding. Nature Biotechnology 17:938. http://dx.doi.org/10.1038/13594

Ragin, C. C., and L. M. Amoroso. 2010. Constructing social research: the unity and diversity of method. Pine Forge, Newbury Park, California, USA.

Ramasar, V. 2014. Fluid governance: scalar politics in the South African waterscape. Dissertation. LUCSUS, Lund University, Lund, Sweden. 
Ramsey, A. 2000. Klassisk och modern samhällsteori. Pages 142-159 in H. Andersen and L. B. Kaspersen, editors. Classical and modern social theory. Blackwell, Oxford, UK.

Ritzer, G., and J. Stepnisky. 2017. Contemporary sociological theory and its classical roots: the basics. SAGE, Thousand Oaks, California, USA.

Scheffer, M. 2009. Critical transitions in nature and society. Princeton University Press, Princeton, New Jersey, USA.

Sen, A. 1999. On ethics and economics. Blackwell, Oxford, UK.

Shahadu, H. 2016. Towards an umbrella science of sustainability. Sustainability Science 11:777-788. http://dx.doi.org/10.1007/ s11625-016-0375-3

Sjöström, C. 2015. Food for naught: the politics of food in agricultural modernization for African smallholder food security. Dissertation. LUCSUS, Lund University, Lund, Sweden.

Thorén, H. 2015. The hammer and the nail: interdisciplinarity and problem solving in sustainability science. Dissertation. Department of Philosophy, Lund University, Lund, Sweden.

Valencia, S. 2016. Caught between spaces: socio-environmental vulnerability in formal and informal peri-urban Bogotá and Soacha, Colombia. Dissertation. LUCSUS, Lund University, Lund, Sweden.

Warlenius, R. 2017. Asymmetries: conceptualizing environmental inequalities as ecological debt and ecologically unequal exchange. Dissertation. Faculty of Social Sciences, Lund University, Lund, Sweden.

Wright, E. O. 2010. Envisioning real utopias. Verso, London, UK.

Yengoh, G. T. 2013. Explaining agricultural yield gaps in Cameroon. Dissertation. Department of Physical Geography and Ecosystem Science, Lund University, Lund, Sweden. 
Appendix 1. Our empirical material: $19 \mathrm{PhD}$ dissertations on sustainability.

Andersson, Elina. 2014. Fertile Grounds? Collective strategies and the political ecology of soil management in Uganda. Lund: Lund Dissertations in Sustainability Science.

Bettini, Giovanni. 2013. Climatised Moves. Climate-induced migration and the politics of environmental discourse. Lund: Lund Dissertations in Sustainability Science.

Brandstedt, Eric. 2013. The Construction of Sustainable Development in Times of Climate Change. Lund: Lund Dissertations in Philosophy.

Busch, Henner. 2016. Entangled Cities: transnational municipal climate networks and urban governance. Lund: Lund Dissertations in Sustainability Science.

Carton, Wim. 2016. Fictitious Carbon, Fictitious Change. Environmental Implications of the Commodification of Carbon. Lund: Lund Dissertations in Human Geography.

Hansen, Melissa. 2014. Struggles over conservation space. Social justice in the iSimangaliso Wetland Park, South Africa. Lund: Lund Dissertations in Sustainability Science.

Hildingsson, Roger. 2014. Governing Decarbonisation. The State and the New Politics of Climate Change. Lund: Lund Dissertations in Political Science.

Islar, Mine. 2013. Private Rivers. Politics of renewable energy and the rise of water struggles in Turkey. Lund: Lund Dissertations in Sustainability Science.

Jönsson, Erik. 2013. Fields of Green and Gold. Territorial hunger, rural planning, and the political ecologies of high-end golf. Lund: Lund Dissertations in Human Geography.

Kaijser, Anna. 2014. Who is marching for Pachamama? An intersectional analysis of environmental struggles in Bolivia under the government of Evo Morales. Lund: Lund Dissertations in Sustainability Science.

Krause, Torsten. 2013. Buying Conservation. Financial incentives for tropical forest conservation in the Ecuadorian Amazon. Lund: Lund Dissertations in Sustainability Science.

Lund, Emma. 2013. Hybrid governance in practice. Public and private actors in the Kyoto Protocol's Clean Development Mechanism. Lund: Lund Dissertations in Political Science.

Malm, Andreas. 2014. Fossil Capital: The Rise of Steam-Power in the British Cotton Industry, c. 1825-1848, and the Roots of Global Warming. Lund: Lund Studies in Human Ecology.

Nastar, Maryam, 2014. Navigating Troubled Waters. An analysis of how urban water regimes in the global South reproduce inequality. Lund Dissertations in Sustainability Science.

Ramasar, Vasna. 2014. Fluid Governance. Scalar politics in the South Africa waterscape. Lund: Lund Dissertations in Sustainability Science. 
Sjöström, Cheryl. 2015. Food for Naught. The politics of food in agricultural modernization for African smallholder food security. Lund: Lund Dissertations in Sustainability Science.

Thorén, Henrik. 2015. The Hammar and the Nail. Interdisciplinarity and Problem Solving in sustainability science. Lund: Lund Dissertations in Philosophy.

Valencia, Sandra. 2016. Caught Between Spaces. Socio-Environmental Vulnerability in Formal and Informal Peri-Urban Bogotá and Soacha, Colombia. Lund: Lund Dissertations in Sustainability Science.

Yengoh, Genesis Tambang. 2013. Explaining agricultural yield gaps in Cameroon. Lund: Lund Dissertations from Department of Physical Geography and Ecosystem Science. 